Original Research Paper

\title{
Peningkatan Ketahanan Keluarga Dalam Menghadapi Pandemi Covid-19 Melalui Vaksin dan Pembuatan Ramuan Herbal Peningkat Sistem Imun
}

\author{
Asih Triastuti $^{1,2 *}$, Arde Toga Nugraha ${ }^{1,2}$, Riyanto ${ }^{1}$, Yon Haryanto ${ }^{1}$ \\ ${ }^{I}$ Department of Pharmacy, Universitas Islam Indonesia, Sleman, Indonesia; \\ ${ }^{2}$ Pusat Studi Herbal Department of Pharmacy, Universitas Islam Indonesia, Sleman, Indonesia.
}

https://doi.org/10.29303/jpmpi.v3i2.1259

Sitasi: Triastuti, A., Nugraha, A. T., Riyanto \& Haryanto. (2022). Peningkatan Ketahanan Keluarga Dalam Menghadapi Pandemi Covid-19 Melalui Vaksin dan Pembuatan Ramuan Herbal Peningkat Sistem Imun. Jurnal Pengabdian Magister Pendidikan IPA, 5(1)

\author{
Article history \\ Received: 10 Januari 2022 \\ Revised: 01 Februari 2022 \\ Accepted: 05 Februari 2022 \\ *Corresponding Author: Asih \\ Triastuti, Department of \\ pharmacy,Universitas Islam \\ Indonesia, Sleman, Indonesia \\ Email: asih.triastuti@uii.ac.id
}

\begin{abstract}
Since it was declared a pandemic by the World Health Organization, Covid-19 has significantly altered the behavior and way of life of the global community, as well as the majority of the Indonesian people. This has ramifications for the resilience of families. A strong family resilience will benefit the family's ability to deal with the various impacts and changes caused by the pandemic and post-pandemic problems. According to various reports, community empowerment is critical to the pandemic's success. Communities with a strong health culture, educational and social foundation will be successful in responding to, analyzing, and resolving pandemics (and other health/social problems that may arise) using quantifiable strategies that can actively support the government policies. The purpose of this activity is to foster a society with physically and mentally healthy, educated, and has a healthy culture. The PucungUmbulsari village is located 24 kilometers from the campus of the Univesitas Islam Indonesia, is a partner in this service. Promotional activities for the covid-19 vaccine and the workshop of herbals to boost the immune system are carried out based on the results of the initial need assessment conducted by the proposer and community officials (heads of $\mathrm{RT}$ and RW). The activities are part of the community recovery process, which includes addressing issues that arose during the pandemic and preparing people to adapt to new normal. While maintaining health protocols, health promotion activities and training are conducted. The social impact of this community service activity are an increase in public awareness of the COVID-19 vaccine in preventing the spread of the disease and the high participation and initiative of the society to produce herbals.
\end{abstract}

Keywords: family resilience; vaccine; herbals; immune system; community empowerment

\section{Pendahuluan}

Konsep sehat merupakan "keadaan yang sempurna baik fisik, mental maupun sosial, tidak hanya terbebas dari penyakit atau kelemahan/cacat". Pembangunan kesehatan bertujuan untuk meningkatkan kesadaran, kemauan dan kemampuan seluruh masyarakat untuk hidup sehat guna mencapai derajat kesehatan masyarakat yang setinggi-tingginya sebagaimana diatur dalam Undang-Undang Nomor 17 RPJPN 2005-2025. Salah satu pilar utama pelaksanaan "Indonesia Sehat" adalah dengan penerapan paradigma kesehatan melalui pendekatan keluarga. Penerapan paradigma sehat dilakukan dengan strategi 
penguatan upaya promotif dan preventif, serta pemberdayaan masyarakat dengan berfokus pada penguatan keluarga sebagai unit terkecil komunitas dalam masyarakat (Departemen kesehatan Repubik Indonesia, 2016).

Keluarga menjadi sasaran dalam kegiatan pengabdian ini karena keluarga merupakan ekosistem terkecil dari masyarakat dan merupakan unsur inti penggerak komunitas. Setiap keluarga memiliki peranan penting sebagai pengubah suatu komunitas apabila mereka memiliki nilai dan budaya yang baik dan kuat (KPPA, 2016). Dengan berbasis pendekatan pada keluarga, pengetahuan dan nilai-nilai yang disampaikan selama kegiatan pengabdian diharapkan dapat dilaksanakan secara menyeluruh (karena melibatkan seluruh anggota keluarga) dan berkesinambungan (nilai tersebut diimplementasikan dalam kehidupan sehari-hari) (Kenny, 2020; OXFAM, 2020).

Budaya menjaga kesehatan masih belum diterapkan dengan baik oleh warga Dusun Pucung Umbulsari. Apalagi pada masa pandemi Covid-19 kesadaran dan pengetahuan warga akan bahaya Covid-19 masih rendah dan beberapa golongan masyarakat abai dengan permasalahan tersebut. Selama pandemi, sebelum kegiatan pengabdian masyarakat dilakukan, terdapat 10 warga yang terkonfirmasi positif tekena Covid-19 dan persentase warga yang sudah menerima vaksin Covid-19 baru sekitar $15 \%$.

Diperlukan suatu promosi kesehatan tentang memahami Covid-19 dari segi pencegahan dan kontrolnya di masyarakat. Derasnya arus informasi terkait dengan pengelolaan pembelajaran daring, maraknya informasi keliru (hoaks) atau misinformasi terkait dengan Covid-19 yang ditanggapi kelompok warga secara beragam menggambarkan perbedaan kemampuan dalam penguasaan teknologi dan pemilahan informasi. Hal ini berakibat pada munculnya gesekan di masyarakat dan sempat memunculkan ketidakharmonisan hubungan antar warga di susun tersebut. Permasalahan ini bisa ditangani apabila warga diberikan informasi (KIE) yang benar tentang Covid dan vaksin Covid.

Pada masa pandemi, kebutuhan masyarakat akan obat tradisional untuk meningkatkan sistem imun meningkat pesat. Keterampilan masyarakat dalam mengelola obat herbal dan memproduksi ramuan herbal merupakan salah satu potensi untuk memberdayakan masyarakat dengan sasaran bidang kesehatan dan ekonomi.

Pelatihan tentang informasi ramuan obat herbal yang dapat digunakan untuk meningkatkan sistem imun tubuh dan teknik pembuatannya perlu dilaksanakan.

\section{Metode}

\section{Analisa situasi mitra pengabdian}

RW 32 Dusun Pucung, Kranggan II terletak di bagian timur Kabupaten Sleman, di sebelah barat jalan Prambanan-Wonosari. Dusun Pucung terdiri dari 3 RT, yaitu RT 05, RT 06, dan RT 07 dengan jumlah warga per bulan Februari 2019 adalah 425 orang terdiri dari 197 Laki-laki dan 228 perempuan. Di masing - masing RT, ditemukan jumlah perempuan lebih banyak daripada jumlah laki-laki. Dari segi usia, 264 orang diantaranya atau sekitar $62 \%$ dari total warga di Dusun Pucung berada pada usia produktif (18-60 tahun), 24\% nya merupakan anak-anak dan remaja, dan $14 \%$ nya merupakan penduduk usia lanjut.

Gambaran demografi penduduk dapat dilihat pada gambar 1.

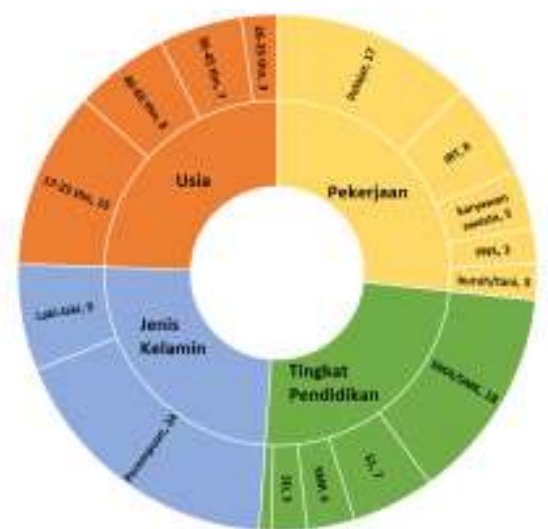

Gambar 1. Gambaran demografi penduduk dusun Pucung - Umbulsari

\section{Tahapan pengabdian}

Kegiatan pengabdian dibagi menjadi 4 tahap, yaitu tahap 1 kegiatan sosialisasi dan need assesment, tahap 2 pembuatan media pengabdian, tahap 3 implementasi program, dan tahap 4 analisis dan pelaporan.

1. Kegiatan tahap 1 merupakan sosialisasi program kepada pamong di dusun yang dilakukan melalui beberapa metode. Pertama, 
melakukan koordinasi dengan ketua RT, ketua $\mathrm{RW}$, dan ketua organisasi pemuda. Kedua, melakukan diskusi kelompok dengan ibu PKK dan anggora organisasi pemuda. Pada tahap ini kebutuhan rinci dari warga untuk program yang akan dilaksanakan dieksplorasi lebih dalam dan dianalisis agar diperoleh pemetaan kebutuhan yang tepat sasaran. Kegiatan ini dilakukan pada bulan Mei 2021. Pada tahap sosialisasi tim PkM mendapatkan masukan dari warga terkait dengan pelaksanaan kegiatan pengabdian yang harus tetap mengedepankan protokol kesehatan (prokes) dalam pelaksanaannya. Usulan dari warga selanjutnya ditindaklanjuti dengan

2. Kegiatan tahap 2 dilakukan pada bulan kedua yang meliputi pembuatan media pengabdian seperti video KIE (promosi kesehatan), poster dan brosur, modul, dan pengadaan bahan pendukung, seperti modul atau media edukasi lainnya. Kegiatan ini dilakukan pada bulan 1 dan 2. Jenis media yang dibuat disesuaikan dengan kebutuhan warga dan sasarannya (remaja atau ibu)

3. Kegiatan tahap 3 adalah implementasi program yang dilaksanakan pada bulan 3-6 meliputi:

[1] Kegiatan pelatihan pembuatan simplisia dan sediaan/ramuan obat tradisional bekerja sama dengan Pusat Studi Obat Herbal (PSOH) UII. Sasaran kegiatan ini adalah ibu-ibu dan remaja putri di lingkungan dusun Pucung - Umbulsari. Diharapkan ibu - ibu dapat memanfaatkan sediaan tanaman obat keluarga yang sudah dikelola kebunnya melalui program pengabdian masyarakat yang merupakan keberlanjutan dari kegiatan pengabdian masyarakat tahun sebelumnya (Nugraha \& Triastuti, 2021). Kegiatan ini juga akan memberikan keterampilan dalam pembuatan ramuan herbal untuk meningkatkan sistem imun yang diharapkan dapat menginisiasi kreativitas ibu PKK.

[2] Kegiatan promosi kesehatan pencegahan penyebaran covid-19 dan vaksin covid-19. Kegiatan ini melibatkan ibu PKK dan pemuda di lingkungan dusun PucungUmbulsari.
Kegiatan tahap 4 adalah analisis dan pelaporan pada bulan ke 7 dan 8 . Analisis data pengabdian masyarakat diperoleh melalui hasil tes/pengukuran indikator sebelum dan sesudah kegiatan selesai dilaksanakan. Pengukuran berupa self-assessment sesuai dari indikator yang akan diukur, baik itu meliputi kognitif maupun keterampilan.

Metode pelaksanaan dari kedua aktivitas di atas menerapkan peer-support model, yaitu memberdayakan individu-individu yang potensial untuk diberikan pelatihan dan promosi kesehatan, sehingga kelompok-kelompok yang sudah mengikuti program ini akan dapat melanjutkan pelatihan dan promosi kesehatan di dalam masyarakat Dusun Pucung-Umbulsari sebelum program berakhir. Diharapkan seluruh aktivitas akan memiliki keberlanjutan dan kebermanfaatan untuk kemandirian masyarakat, khususnya pada aspek kesehatan holistik (fisik, mental, dan spiritual).

\section{Hasil dan Pembahasan}

Kegiatan promosi kesehatan vaksin covid-19 dan pelatihan pembuatan ramuan herbal, mengalami penundaan pelaksanaan dari yang sebelumnya dijadwalkan bulan Juli 2021 menjadi bulan September 2021 disebabkan adanya penerapan Pemberlakuan Pembatan Kegiatan Masyarakat (PPKM) yang diberlakukan mulai 4 Juli 2021. Aktivitas pengabdian dilaksanakan dengan tetap menerapkan prokes dan sasaran warga dipilih yang telah memperoleh vaksinasi Covid-19. Lokasi tempat pengabdian dipilih di tempat/ruang terbuka yaitu di halaman "omah sampah" dan di halaman rumah warga dengan halaman yang luas. Selain itu, disediakan fasilitas prokes seperti hand sanitizer, masker, dan termometer badan (shot gun thermometer). Bukti kegiatan promkes vaksin covid-19 dan gambaran data responden dapat dapat dilihat pada gambar 2, 3, dan 4 .

Pada kegiatan promkes tentang vaksin covid19, narasumber yang diundang adalah Dr. apt. Arba Pramundita, M.Sc. sebelum diberikan penyuluhan, peserta diminta untuk mengisi pre-test untuk melihat tingkat pengetahuan sebelum diberikan penyuluhan. Setelah penyuluhan selesai, tingkat pemahaman warga diukur dengan post-test (gambar 4). 


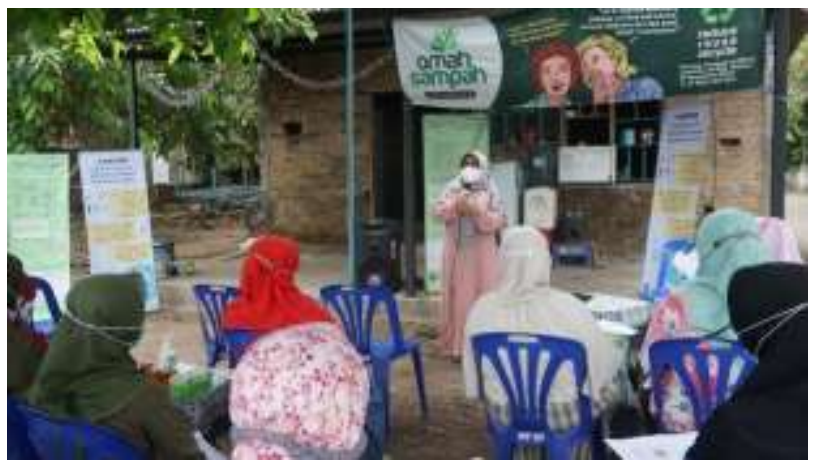

Gambar 2. Pelaksanaan promosi vaksin covid-19

Kegiatan pelatihan pembuatan ramuan herbal dibantu oleh mahasiswa anggota PSOH UII. Ramuan herbal yang dibuat berisi serbuk tanaman obat yang secara empiris telah terbukti dapat meningkatkan sistem imun seperti kayu secang, jahe, temulawak, kembang telang, kayu manis, dan kunyit.

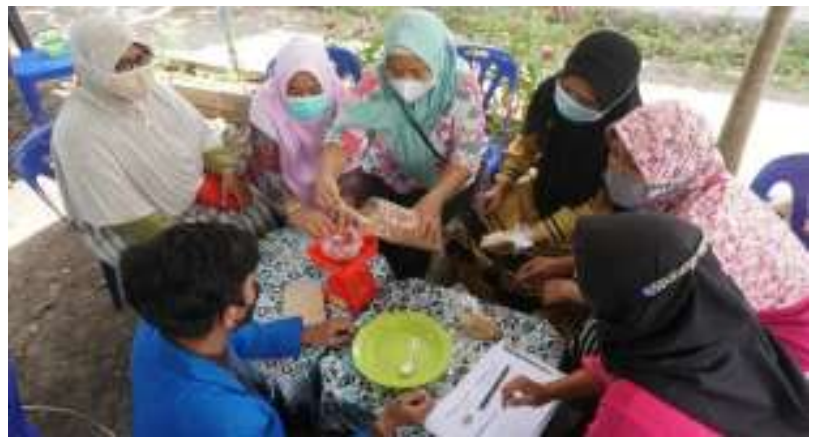

Gambar 3. Pelatihan pembuatan ramuan herbal peningkat sistem imun

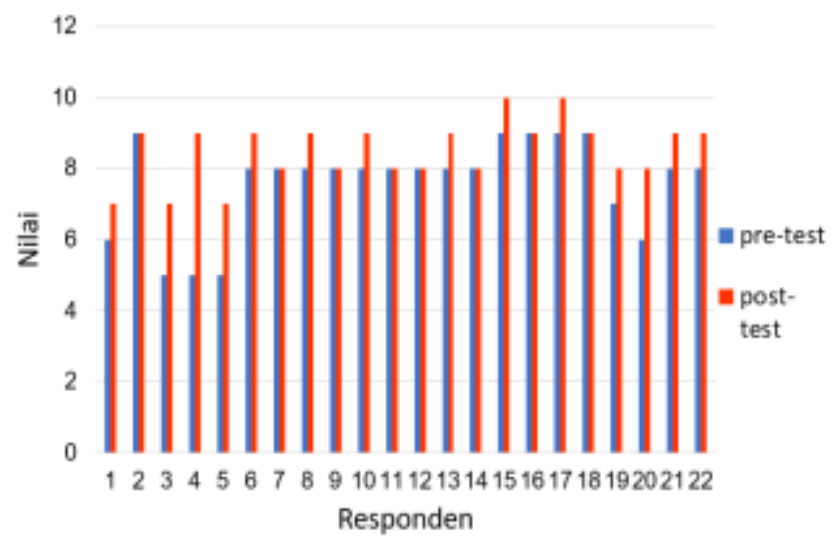

Gambar 4. Hasil evaluasi pengetahuan warga tentang vaksin covid-19 sebelum dan sesudah promosi kesehatan dilakukan.
Dari gambar 4 terlihat terjadi kenaikan tingkat pemahaman peserta penyuluhan dengan nilai ratarata pre-test 7,5 menjadi 8,5. Peserta juga mengisi kuesioner tentang pandemik covid-19, kesediaan ikut vaksin, dan informasi terkait dengan protokol kesehatan untuk menghadapi era tatanan baru.

Luaran dari kegiatan pengabdian kepada masyarakat diantaranya :

[1] Publikasi di media elektronik (website PSOH UII): Fixitindo.com/pharmacy_uii di link

https://fixitindo.com/pharmacy uii/single page.php? $\mathrm{m}=20$

Dan link:

https://fixitindo.com/pharmacy_uii/single_ page.php? $m=26$

[2] Video promosi Vaksin Covid-19 dan pembuatan obat herbal di youtube: https://youtu.be/JwT_0uJHbwk

Video tersebut telah didaftarkan atas HAKI dengan nomor pendaftaran EC00202166608.

[3] Keterampilan warga membuat ramuan herbal meningkat. Warga secara mandiri melakukan pelatihan pembuatan teh celup pada tanggal 19 September 2021 bertempat di rumah ketua RW 32 (gambar 5). Berdasarkan hasil evaluasi, ketua RW 32 menyatakan keinginan warga untuk meminta bantuan kepada PSOH UII agar dapat melanjutkan kegiatan pembuatan obat herbal dengan tujuan jangka panjang meningkatkan ekonomi warga. Hal ini ditanggapi oleh tim PkM dan PSOH UII dengan merancang kegiatan pembuatan simplisia dan produk herbal yang direncanakan akan dilaksanakan pada tahun 2022 dengan pembiayaan dari hibah pengabdian masyarakat DPPM UII dengan nomor kontrak: 4 / Dir/ DPPM/80/ DesaMitra/XI/2021.

[4] Peningkatan pengetahuan dan kesadaran warga akan pentingnya vaksinasi covid-19 meningkat. Dampak sosial juga terlihat dari adanya kegiatan promkes vaksin Covid-19. Jumlah warga yang telah menerima vaksin covid-19 setelah dilakukannya promosi kesehatan vaksin Covid-19 sudah hampir 90\%. Hal ini juga didukung oleh adanya kegiatan "serbuan 1000 vaksin" yang 
diprakarsai oleh karang taruna dusun Pucung - Umbulsari "Setia Pura" bekerjasama dengan pemerintah Kelurahan Jogotirto dan Angkatan Laut RI.

\section{Kesimpulan}

Kegiatan pengabdian dapat dilaksanakan dengan baik dan mendapat dukungan positif dari warga. Semua luaran telah tercapai berikut dampak social dan dampak ekonomi juga sudah terlihat di Dusun Pucung - Umbulsari. Kegiatan tertunda pelaksanaannya diakibatkan karena adanya aturan pembatasan berkelompok PPKM sejak 4 Juli 2021 tetap dapat terlaksana dengan menerapkan protokol kesehatan.

\section{Ucapan Terima Kasih}

Ucapan terima kasih ditujukan kepada Direktorat Riset dan Pengabdian Masyarakat Deputi Bidang Penguatan Riset dan Pengembangan Kementerian Riset dan Teknologi / Badan Riset dan Inovasi Nasional yang telah membiayai program ini Sesuai dengan Kontrak Pengabdian kepada Masyarakat Pelaksanaan Program Pengabdian Masyarakat Nomor: 088/SP2H/PPM/DRPM/2021.

\section{Daftar Pustaka}

Departemen kesehatan Repubik Indonesia. (2016). Pedoman Umum Program Indonesia Sehat Dengan Pendekatan Keluarga. DepKes RI.

Kenny, S. (2020). Covid-19 and community development. Community Development Journal, $\quad 00(00), \quad 1-5$. https://doi.org/10.1093/cdj/bsaa020

KPPA. (2016). Pembangunan Ketahanan Keluarga. Journal of Petrology. CV Lintas Khatulistiwa. Retrieved from http://dx.doi.org/10.1080/00206814.2014.

Nugraha, A. T., \& Triastuti, A. (2021). Peningkatan Asuhan Kemandirian Penggunaan Tanaman Obat Pada Kader PKK di Dusun Pucung Kranggan II Berbah Sleman Yogyakarta, 1-4.

OXFAM. (2020). Community engagement during Covid-19. Oxfam. 